\title{
Maternal C-Peptide and Insulin Sensitivity, but Not BMI, Associate with Fatty Acids in the First Trimester of Pregnancy
}

\author{
Julia Bandres-Meriz ${ }^{1, *}$, Alejandro Majali-Martinez ${ }^{1} \oplus$, Denise Hoch ${ }^{1} \oplus$, Milagros Morante ${ }^{2}$, Andreas Glasner ${ }^{3}$, \\ Mireille N. M. van Poppel ${ }^{4}\left(\mathbb{D}\right.$, Gernot Desoye ${ }^{1, *} * \mathbb{1}$ and Emilio Herrera ${ }^{2}$ \\ 1 Department of Obstetrics and Gynaecology, Medical University of Graz, 8036 Graz, Austria; \\ a.majali-martinez@medunigraz.at (A.M.-M.); denise.hoch@medunigraz.at (D.H.) \\ 2 Faculty of Pharmacy, Universidad San Pablo CEU, 28668 Madrid, Spain; morantesantana@gmail.com (M.M.); \\ eherrera@ceu.es (E.H.) \\ 3 Femina Med-Center, 8010 Graz, Austria; office@dr-glasner.at \\ 4 Institute of Human Movement Science, Sport and Health, University of Graz, 8010 Graz, Austria; \\ mireille.van-poppel@uni-graz.at \\ * Correspondence: julia.bandres-meriz@medunigraz.at (J.B.-M.); gernot.desoye@medunigraz.at (G.D.); \\ Tel.: +43-316-385-17841 (J.B.-M.); +43-316-385-14605 (G.D.)
}

Citation: Bandres-Meriz, J.; Majali-Martinez, A.; Hoch, D.; Morante, M.; Glasner, A.; van Poppel, M.N.M.; Desoye, G.; Herrera, E. Maternal C-Peptide and Insulin Sensitivity, but Not BMI, Associate with Fatty Acids in the First Trimester of Pregnancy. Int. J. Mol. Sci. 2021, 22, 10422. https://doi.org/10.3390/ ijms221910422

Academic Editor:

Marie-Pierre Piccinni

Received: 17 August 2021

Accepted: 24 September 2021

Published: 27 September 2021

Publisher's Note: MDPI stays neutral with regard to jurisdictional claims in published maps and institutional affiliations.

Copyright: (C) 2021 by the authors. Licensee MDPI, Basel, Switzerland. This article is an open access article distributed under the terms and conditions of the Creative Commons Attribution (CC BY) license (https:// creativecommons.org/licenses/by/ $4.0 /)$.
Abstract: Maternal obesity in pregnancy is a pro-inflammatory condition exposing the fetus to an adverse environment. Here, we tested associations of maternal obesity (primary exposures: BMI, leptin) and metabolic parameters (secondary exposures: glucose, C-peptide, and insulin sensitivity) with total serum concentrations of fatty acids in the first trimester of human pregnancy. This cross-sectional study included 123 non-smoking women with singleton pregnancy. In maternal serum, cotinine, leptin, and C-peptide (ELISA), glucose (hexokinase-based test) and fatty acids (gas chromatography) were quantified, and the insulin sensitivity index ( IS $_{\mathrm{HOMA}}$ ) was calculated. Concentrations of fatty acid classes and total fatty acids did not differ between BMI or leptin categories. However, $n-3$ polyunsaturated fatty acids (PUFA) were decreased in the category with the highest C-peptide concentration $(n-3$ PUFA: CI $-35.82--6.28, p<0.006)$ and in the lowest IS HOMA category ( $n-3$ PUFA: CI $-36.48--5.61, p<0.008)$. In a subcohort, in which fetal sex was determined (RT-qPCR of placental tissue), C-peptide was significantly associated with docosahexaenoic acid (DHA) in mothers bearing a female $(n=46)$, but not male $(n=37)$ fetus. In conclusion, pregnant women with high fasting C-peptide and low IS $_{\text {HOMA }}$ had decreased $n-3$ PUFA, and DHA was lower with higher C-peptide only in mothers bearing a female fetus.

Keywords: early pregnancy; obesity; fatty acids; glucose; C-peptide; insulin sensitivity; fetal sex

\section{Introduction}

The prevalence of obesity in women of reproductive age is increasing worldwide. In pregnancy, obesity exposes the fetus to an adverse intrauterine environment. This often results in short- and long-term health consequences, including altered fetal neurodevelopment, increased fetal growth, increased neonatal adiposity, and a higher risk for the development of cognitive and behavioral disorders and obesity early in life [1-4].

Women who are obese frequently develop gestational diabetes mellitus (GDM) in pregnancy [5] and both obesity and diabetes are characterized by chronic low-grade inflammation [6].

While the strong effect of hyperglycemia on fetal growth has been well established [7,8], there are increasing arguments suggesting that triglycerides and non-esterified fatty acids (NEFA) also contribute to fetal overgrowth $[9,10]$. Indeed, it has been proposed that altered lipid metabolism rather than hyperglycemia constitutes a risk for macrosomia in GDM [11]. Likewise, maternal long-chain polyunsaturated fatty acids (PUFA) have been associated with cognitive and behavioral performance in childhood [12], and decreased maternal $n-3$ PUFA concentrations correlate with lower brain volume in the offspring [13]. 
Maternal lipid metabolism changes profoundly during pregnancy [14]. Early pregnancy is an anabolic state with increased storage of fat in the mother that will serve as a source of nutrients for the fetus later in pregnancy when the mother is in a catabolic state $[15,16]$. Maternal lipids, especially fatty acids, are important contributors to building up maternal fat stores and to fetal adiposity. Alterations of fatty acid concentrations in the second half of pregnancy by conditions such as maternal obesity have been well recognized $[17,18]$. However, to the best of our knowledge, the effects of maternal obesity on fatty acids and the associated changes in the glucose-insulin axis [19] in the first trimester of pregnancy have not been investigated yet.

In the present study, we tested the potential association of maternal obesity (primary exposures: BMI, leptin) with fasting fatty acids concentrations in the first trimester of human pregnancy. Because obesity is a heterogeneous condition with a proportion of subjects having normal metabolism [20], we also included metabolic parameters (secondary exposures: glucose, C-peptide, and IS $_{\mathrm{HOMA}}$ ) to delineate potential metabolic pathways. Increasing evidence suggests a contribution of fetal sex to maternal metabolism [21-23]. To assess potential interactions between fetal sex and maternal metabolic parameters, we performed secondary analyses in a subcohort in which fetal sex was determined.

\section{Results}

\subsection{Maternal BMI and Leptin Do Not Associate with Fatty Acid Concentrations}

The concentration of total fatty acids, SFA, MUFA, $n-3$ PUFA, or n-6 PUFA did not differ between $\mathrm{BMI}$ or leptin groups (Figure $1 \mathrm{~A}$ ). Among the individual fatty acids, myristic acid (C 14:0) was decreased ( $\beta$ : $-0.20, \mathrm{CI}:-0.39--0.01, p=0.037)$ in the overweight group (BMI $25-29.9 \mathrm{~kg} / \mathrm{m}^{2}$ ) compared to the referent category (BMI $<25 \mathrm{~kg} / \mathrm{m}^{2}$ ) (Table S1), which was not statistically significant after correcting for multiple testing. No differences were found between leptin categories, with the exception of dihomo- $Y$-linolenic acid (C 20:3 $n-6$ ), that was increased ( $\beta: 6.22, \mathrm{CI}: 0.19-12.25, p=0.043$ ) in the group with high leptin (leptin $\geq 15.3 \mathrm{ng} / \mathrm{mL}$ ) compared to the referent group (leptin $<8.5 \mathrm{ng} / \mathrm{mL}$ ). Again, the association lost statistical significance after correcting for multiple testing (Figure 1B, Table S1).

\subsection{High Glucose Associates with Decreased SFA Concentration}

SFAs were decreased ( $\beta$ : $-80.54, \mathrm{CI}:-159.29--1.79, p=0.045)$ in the tertile with the highest glucose concentration $(\geq 4.97 \mathrm{mmol} / \mathrm{L})$ compared to the referent category $(<4.28 \mathrm{mmol} / \mathrm{L})$, but the association was not significant after correcting for multiple testing (Figure 1C). Palmitic acid (C 16:0) was the most abundant (67.1\%) SFA and it was significantly decreased in the tertile with the highest glucose concentration $(\beta$ : -0.11 , CI: $-0.22--0.01, p=0.032$ ) (Table S1, Figure S1). However, the association lost statistical significance after correcting for multiple testing.

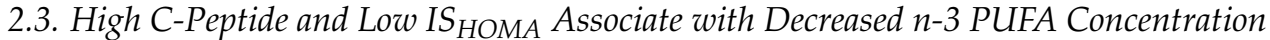

The tertile with the highest C-peptide $(\geq 437.8 \mathrm{pmol} / \mathrm{L})$ had decreased $(\beta:-21.05$, CI: $-35.82--6.28, p=0.006) n-3$ PUFA concentration compared to the referent category (C-peptide $<315.4 \mathrm{pmol} / \mathrm{L}$ ) (Figure 1D). The tertile with the lowest insulin sensitivity $\left(\mathrm{IS}_{\text {HOMA }} \leq 0.59\right)$ also had lower $n-3$ PUFA concentrations $(\beta:-21.05, \mathrm{CI}:-36.48--5.61$, $p=0.008)$ compared to the referent category (IS HOMA $>0.85$ ) (Figure 1E). Both associations remained significant after correcting for multiple testing. 
A BMI

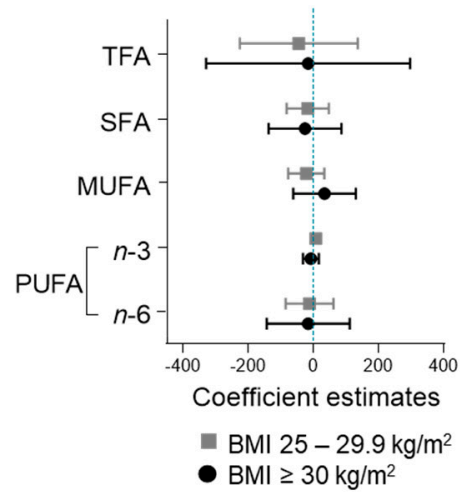

C Glucose

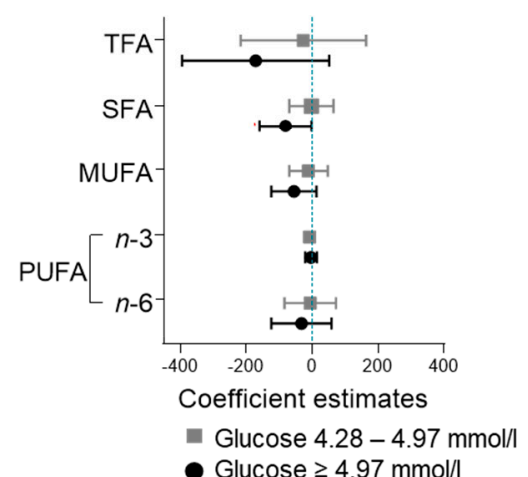

B Leptin

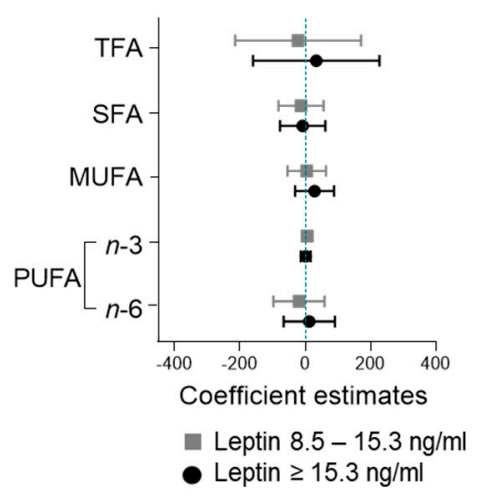

D C-peptide

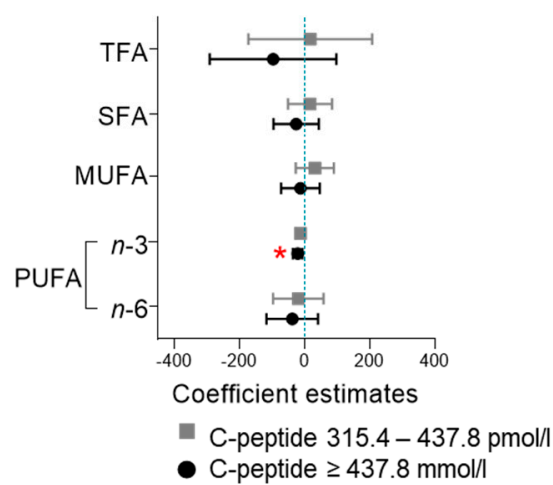

E IS HOMA

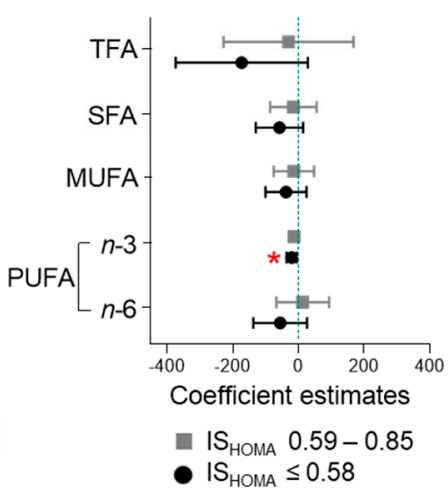

Figure 1. Maternal C-peptide and IS $_{\mathrm{HOMA}}$, but not maternal BMI or leptin, associate with $n-3$ PUFA. Measures of maternal obesity (BMI) (A), adiposity (leptin) (B) and of the glucose-insulin axis (glucose, C-peptide, and IS HOMA $_{\text {) }}$ (C-E) were categorized into tertiles and the estimates compared to the reference category: $\mathrm{BMI}<25 \mathrm{~kg} / \mathrm{m}^{2}$, leptin $<8.5 \mathrm{ng} / \mathrm{mL}$, glucose $<4.28 \mathrm{mmol} / \mathrm{L}$, C-peptide < $315.4 \mathrm{pmol} / \mathrm{L}$, IS HOMA $_{3}>0.85$. SFA: sum of 14:0, 16:0, and 18:0; MUFA: sum of 16:1, 18:1, and 22:1; n-3 PUFA: sum of 18:3, 20:3, 20:5, 22:5, and 22:6; n-6 PUFA: sum of 18:2, 18:3, 20:3, 20:4, 22:2, 22:4, and 22:5. Model adjusted for gestational age (days), maternal age (years) and processing time (minutes). ${ }^{*}$ Statistically significant difference after correction for multiple testing (FDR $=0.2$ ).

Next, we wanted to identify the individual fatty acids associating with C-peptide and IS $_{\text {HOMA, }}$ respectively. Eicosatrienoic acid (C 20:3 n-3; 3.1\% of total $n-3$ PUFAs, $p=0.008$ ), eicosapentaenoic acid (C 20:5 n-3; 10.8\% of total $n-3$ PUFAs, $p=0.043$ ), and docosapentaenoic acid (C 22:5 $n-3 ; 16.7 \%$ of total $n$-3 PUFAs, $p=0.029$ ) concentrations were decreased in the tertile with the highest C-peptide ( $\geq 437.8 \mathrm{pmol} / \mathrm{L})$. Based on $\beta$ estimates, C-peptide had the strongest association with docosapentaenoic acid (C 22:5n-3). Eicosatrienoic acid (C 20:3 n-3) was also decreased in the 2nd tertile (C-peptide 315.4-437.8 pmol/L $p=0.001$ ) (Figure 2A). Docosapentaenoic acid (C 22:5 $n-3 ; p=0.026$ ) was also significantly decreased in the low IS $_{\text {HOMA }}$ group $\left(\mathrm{IS}_{\mathrm{HOMA}} \leq 0.59\right)$ (Figure $2 \mathrm{~B}$ ). All those associations remained significant after adjusting for multiple testing (adjustment including all tests performed between C-peptide and $\mathrm{IS}_{\mathrm{HOMA}}$ and the individual $n-3$ PUFA; $\mathrm{n}=20$ ) (Figure 2).

\subsection{High C-Peptide and Low IS HOMA Associate with n-6/n-3 PUFA Ratio}

Fasting serum C-peptide (continuous) was significantly associated with the $n-6 / n-3$ PUFA ratio ( $\beta: 0.69$, CI: $0.12-1.45, p=0.018$ ) (Table 1 ). IS HOMA $_{\text {HOntinuous) was inversely }}$ associated with the $n-6 / n-3$ PUFA ratio ( $\beta$ : -0.59 , CI: $-1.09-0.87, p=0.022)$ (Table 1$)$, also after correction for multiple testing. 


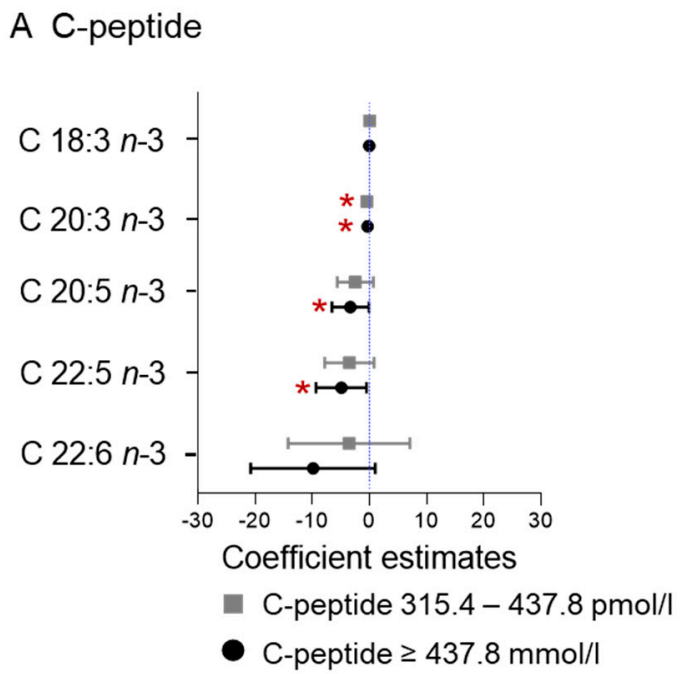

B IS HOMA

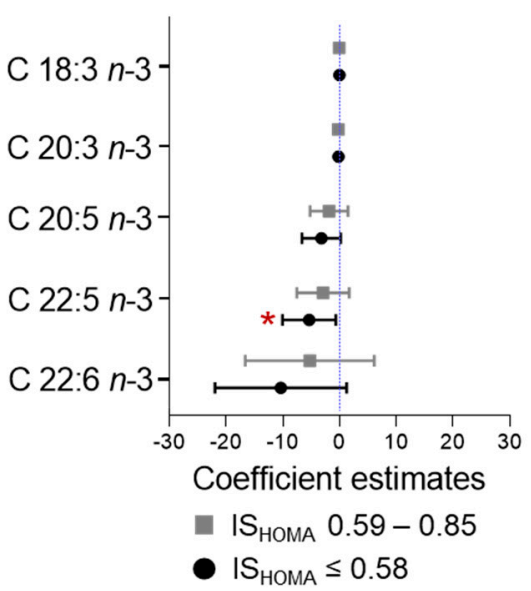

Figure 2. Association of C-peptide and IS $_{\text {HOMA }}$ with individual n-3 fatty acids. Measures of maternal C-peptide (A) and $\mathrm{IS}_{\mathrm{HOMA}}(\mathbf{B})$ were categorized into tertiles and the estimates compared to the reference category: C-peptide $<315.4 \mathrm{pmol} / \mathrm{L}$, ISHOMA $>0.85$. Model adjusted for gestational age (days), maternal age (years), and processing time (minutes). * Statistically significant difference after correction for multiple testing $(\mathrm{FDR}=0.2)$.

Table 1. Associations between C-peptide or $\mathrm{IS}_{\mathrm{HOMA}}$ and fatty acids classes are independent of BMI and leptin.

\begin{tabular}{|c|c|c|c|c|c|c|c|c|c|c|}
\hline & & \multicolumn{3}{|c|}{ Model 1} & \multicolumn{3}{|c|}{ Model 2} & \multicolumn{3}{|c|}{ Model 3} \\
\hline & & $\beta$ & $C I$ & $p$ & $\beta$ & $C I$ & $p$ & $\beta$ & $C I$ & $p$ \\
\hline \multirow{5}{*}{ 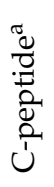 } & Total fatty acids & -14.9 & $-201.4-171.7$ & 0.875 & -7.5 & $-202.1-187.1$ & 0.939 & -43.3 & $-243.0-156.5$ & 0.669 \\
\hline & SFA & 0.6 & $-66.0-67.3$ & 0.985 & 6.5 & $-62.9-75.9$ & 0.853 & -0.7 & $-72.3-70.8$ & 0.984 \\
\hline & MUFA & 19.0 & $-38.3-76.3$ & 0.512 & 21.2 & $-38.5-81.0$ & 0.483 & 8.5 & $-52.7-69.8$ & 0.783 \\
\hline & PUFA $n-3$ & -17.0 & $-31.2--2.8$ & 0.019 & -17.1 & $-32.0--2.3$ & 0.024 & -21.5 & $-36.5--6.4$ & 0.006 \\
\hline & PUFA $n-6$ & -17.5 & $-93.25--58.3$ & 0.648 & -18.1 & $-97.1-61.0$ & 0.652 & -29.7 & $-110.8--51.4$ & 0.470 \\
\hline \multirow{7}{*}{ 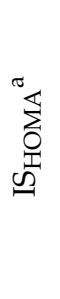 } & Ratio $n-6 / n-3$ & 0.69 & $0.12-1.25$ & 0.018 & 0.69 & $0.10-1.28$ & 0.022 & 0.78 & $0.17-1.38$ & 0.012 \\
\hline & Total fatty acids & 35.0 & $-131.2-201.3$ & 0.677 & 30.9 & $-142.1-203.8$ & 0.677 & 69.6 & $-111.4-250.5$ & 0.448 \\
\hline & SFA & 10.5 & $-48.9-69.9$ & 0.727 & 6.5 & $-55.2-68.1$ & 0.836 & 14.4 & $-50.4-79.2$ & 0.661 \\
\hline & MUFA & -8.5 & $-59.7-42.6$ & 0.742 & -9.1 & $-62.3-44.1$ & 0.735 & 3.3 & $-52.3-58.8$ & 0.908 \\
\hline & PUFA $n-3$ & 15.1 & $2.5-27.8$ & 0.020 & 15.2 & $2.0-28.3$ & 0.025 & 20.1 & $6.4-33.7$ & 0.004 \\
\hline & PUFA $n-6$ & 18.0 & $-49.6-85.5$ & 0.599 & 18.4 & $-51.9-88.6$ & 0.605 & 31.8 & $-41.6-105.3$ & 0.392 \\
\hline & Ratio $n-6 / n-3$ & -0.59 & $-1.09--0.09$ & 0.022 & $\begin{array}{l}-0- \\
0.59\end{array}$ & $-1.12--0.07$ & 0.027 & -0.69 & $-1.24--1.14$ & 0.014 \\
\hline
\end{tabular}

Model 1: adjusted for gestational age, maternal age, and processing time. Model 2: Model $1+$ BMI adjustment. Model 3: Model $1+$ leptin adjustment. Bold: Statistically significant difference after correction for multiple testing (FDR = 0.2). $\beta$ : $\beta$ estimate; CI: $95 \%$ confidence interval. SFA: sum of 14:0, 16:0, and 18:0; MUFA: sum of 16:1, 18:1, and 22:1; $n$-3 PUFA: sum of 18:3, 20:3, 20:5, 22:5, and 22:6; $n$-6 PUFA: sum of 18:2, 18:3, 20:3, 20:4, 22:2, 22:4, and 22:5. An ln-transformed variable. Non-normally distributed variables were ln-transformed to meet the requirements of multivariate linear regression analysis. Each $1 \%$ increase in the predictor variable (C-peptide and ISHOMA) increases the outcome variable by $1 / 100$ units of the estimate. For example, a $1 \%$ increase in C-peptide is associated with a $0.17 \mathrm{mg} / \mathrm{L}$ decrease in $n$-3 PUFA.

\subsection{Indices of Desaturase Activities}

None of the metabolic parameters considered in this study (BMI, leptin, glucose, C-peptide and IS $_{\text {HOMA }}$ ) were associated with the ratios palmitoleic acid (C 16:1)/palmitic acid (C 16:0), Y-linolenic acid (C 18:3n-6)/linoleic acid (C 18:2 n-6), and arachidonic acid (C 20:4)/dihomo- $Y$-linolenic acid (C 20:3) representing the indices of $\Delta 9-\Delta 6$ - and $\Delta 5$-desaturase activity, respectively. The ratio of arachidonic acid (C 20:4 n-6)/linoleic acid (C 18:2 $n$-6) reflecting combined elongase, $\Delta 5-$, and $\Delta 6$ - indices of desaturase activity was positively associated with BMI (continuous) (B: 1.16 CI: $0.09-0.22, p=0.00001$ ) after correcting for multiple testing (not shown). 


\subsection{Fetal Sex}

We determined fetal sex whenever placental tissue was available $(n=83)$. Gestational age and maternal metabolic parameters (age, BMI, leptin, glucose, C-peptide, IS $_{\mathrm{HOMA}}$, and fatty acids concentration) did not statistically differ between this subgroup (female $n=46$, male $\mathrm{n}=37)$ and the total cohort (Table S2). Maternal BMI was significantly $(p=0.021)$ higher in female-bearing mothers compared to male-bearing fetuses (Table S4).

There was a significant interaction between fetal sex and BMI $(p=0.076)$, fetal sex and C-peptide $(p=0.072)$, and fetal sex and $\mathrm{IS}_{\text {HOMA }}(p<0.070)$ in the model for total $n$-3 PUFA, that remained significant after correcting for multiple testing. Therefore, we analyzed associations separately for women bearing a female or a male fetus. However, no significant associations between BMI, C-peptide, or ISHOMA with total n-3 PUFA concentration were found in female-bearing mothers nor in the male-bearing mothers. Among the individual $n-3$ PUFA, there was a significant interaction $(p<0.1)$ between fetal sex and C-peptide in the docosahexaenoic acid model (C 22:6n-3), also after adjusting for multiple testing. Further subanalyses showed that the association between C-peptide and docosahexaenoic acid was specific for the female-bearing mothers (Figure 3). Adjusting for BMI or leptin did not significantly change the effect size (model 1: $23.3 \%$ model 2: $24.3 \%$ model 3: $24.1 \%$ ) (Table S5). No significant interactions (all $p>0.1$ ) were found between fetal sex and the exposure variables (BMI, leptin, glucose, C-peptide, or IS $_{\text {HOMA }}$ ) in the SFA, MUFA, or n-6 PUFA models.

A Association between C-peptide and DHA

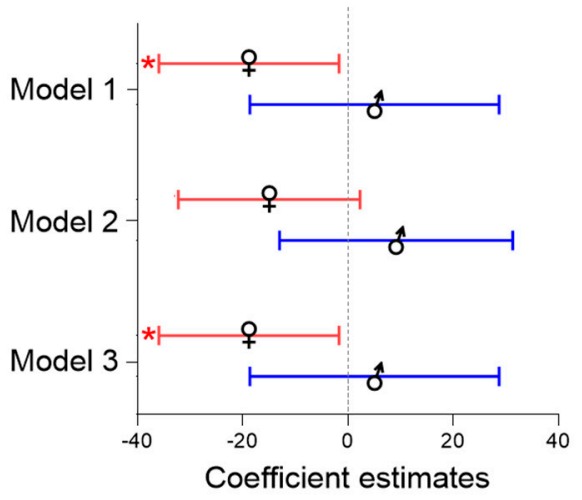

B Female-bearing mothers

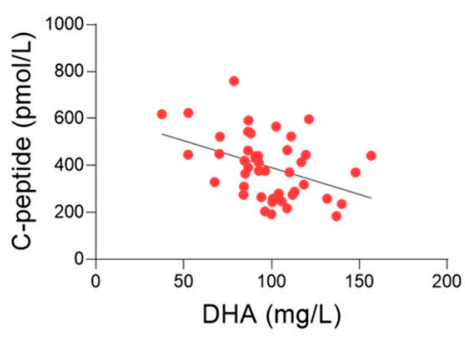

$R^{2}=0.262$

$p$-value $=0.041$
C Male-bearing mothers

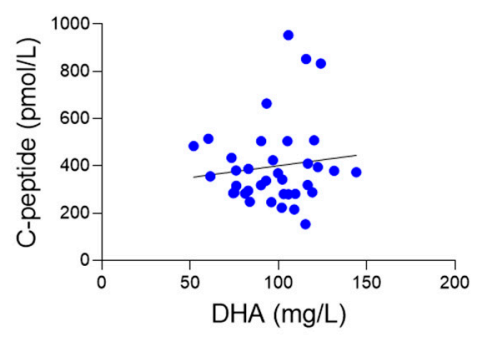

$R^{2}=0.135$

$p$-value $=0.366$

Figure 3. The association between C-peptide and docosahexaenoic acid is specific for female-bearing mothers. (A) Representation of the association between C-peptide and docosahexaenoic acid (DHA) in the female $(n=46)$ and male $(n=37)$ subgroups (Model 1: Adjusted for gestational age, maternal age and processing time, Model 2: Model $1+$ Adjustment for BMI; Model 3: Model 1 + Adjustment for leptin). (B) Correlation between C-peptide and docosahexaenoic acid in the female subgroup. (C) Correlation between C-peptide and docosahexaenoic acid in the male subgroup. ${ }^{*}$ Statistically significant difference after correction for multiple testing $(\mathrm{FDR}=0.2)$.

\subsection{Sensitivity Analysis Excluding Women with High Fasting Glucose}

Women with known co-morbidities, e.g., diagnosed with diabetes, were excluded from the study. However, two women included in the study had fasting serum glucose concentration $>7 \mathrm{mmol} / \mathrm{L}$ [24] $(7.2 \mathrm{mmol} / \mathrm{L}$ and $8 \mathrm{mmol} / \mathrm{L}$, respectively). To rule out a potential driving effect of these women on the results, we performed a sensitivity analysis excluding these values and re-analyzing the data. The analyses provided comparable results (Table S2 and Figure S2). The associations between BMI, leptin, C-peptide, and $\mathrm{IS}_{\mathrm{HOMA}}$ with the fatty acid classes and the individual fatty acids also provided comparable results after excluding these women. 


\section{Discussion}

In the present study, we aimed to test if maternal obesity and adiposity, characterized by BMI and circulating levels of leptin, alter serum fatty acid concentrations already during the first trimester of pregnancy in non-smoking women. We also aimed to identify if potential associations exist between maternal fasting glucose, C-peptide, and IS $\mathrm{S}_{\mathrm{HOMA}}$ and serum fatty acids in this cohort. We found that higher C-peptide and lower $\mathrm{IS}_{\mathrm{HOMA}}$, but not BMI or leptin, were associated with lower serum total $n-3$ PUFA concentrations in the first trimester of pregnancy. Further sub-analyses considering fetal sex showed an association between C-peptide and docosahexaenoic acid (DHA, C 22:6n-3) specific for the female-bearing mothers.

Outside of pregnancy, obesity often associates with hyperinsulinemia and we also recently observed an association between obesity and C-peptide in the first trimester of pregnancy [19]. In the present study, BMI was associated with C-peptide, but not with fatty acid concentrations. The association between C-peptide and $n-3$ PUFA concentration was independent of BMI since the adjustments barely changed $\beta$-estimates and effect size. Adjusting for maternal leptin as a proxy for fat mass resulted in even stronger associations.

Obesity is a heterogeneous condition and up to about $30 \%$ of the obese adult population are metabolically normal with normal lipids and HOMA-insulin resistance [20]. Our study was not designed to distinguish between metabolically normal and abnormal obese women. Therefore, we cannot exclude that such heterogeneity in our cohort, if present at all, may have masked a potential BMI association with the fatty acids. However, the results suggest that using obesity proxies such as BMI might not be well suited to understand metabolism in the first trimester of pregnancy.

Decreased proportions of $n-3$ PUFA in obese children [25] and adults [26] have been previously reported. In an observational case-control study [25] comprising 67 obese and 67 normal-weight children (8-12 years), plasma $n-3$ PUFA and docosahexaenoic acid (DHA, C 22:6n-3) were lower in the highly obese children despite increased consumption (grams and \%) of $n$-3 PUFA in this group. Similar to our study, the concentration of the essential fatty acid $\alpha$-linolenic acid (C 18:3n-3) was not significantly different between groups, suggesting that a dysregulation in the desaturation and elongation steps might take place in obese individuals. In the same study, obese children had significantly higher insulin concentrations, which raises the question of whether the observed changes in $n$-3 PUFA metabolism may be attributed to the hyperinsulinemia associated with obesity. Indeed, outside pregnancy, $n-3$ PUFA supplementation has been shown to improve insulin sensitivity without changes in BMI [27]. In a rat model, $n-3$ PUFA supplementation inhibited toll-like receptor 4 (TLR4) activation in the muscle and resulted in improved insulin sensitivity [28], suggesting that $n-3$ PUFA exert anti-inflammatory properties capable of ameliorating insulin resistance.

Among the individual $n$-3 PUFA, docosahexaenoic acid (DHA, C 22:6n-3) concentration in maternal plasma positively associates with insulin sensitivity [29]. As a speculation, this insulin -ensitizing effect may be mediated through docosahexaenoic acid derivatives such as protectins, resolvins, and maresins. These anti-inflammatory molecules enhance hepatic $\beta$-oxidation, suppress lipogenesis, and stimulate adipokine secretion [30]. However, we cannot conclude whether the decreased serum concentration of $n-3$ PUFA is a cause or a consequence of the altered glucose-insulin axis.

We found an association between C-peptide and docosahexaenoic acid (DHA, C 22:6n-3) in mothers bearing a female, but not when bearing a male, fetus. If confirmed in a larger cohort, this would add to the growing evidence of fetal sex influences on metabolism of the pregnant woman. Fetal sex through placental signals may modify maternal metabolic adaptations to pregnancy $[9,23]$. Interestingly, it has been shown that female placentas are more responsive to maternal dietary supplementation with $n$-3 PUFA [31].

Our study has several strengths. First, fatty acids were measured as concentrations rather than proportions (\%) of fatty acids allowing us to identify changes in one fatty acid without being affected by that of others. Second, we covered a wide gestational age 
range within the first trimester (week $4^{+0}-11^{+6}$ ). Third, smoking was objectively measured and smokers were excluded. This is important because of the known effect of smoking on fatty acids outside [32] and within pregnancy [33-35]. Some limitations deserve a comment. We do not have information on maternal diet, which is the sole source of essential fatty acids and the main source of long-chain PUFAs. However, if diet were to have an effect, then one would expect profound variation in the data for essential fatty acids, which was not observed here. Furthermore, the specific association between Cpeptide and docosahexaenoic acid (DHA, C 22:6n-3) in female-bearing mothers argues for differences in the metabolism of $n-3$ PUFAs rather than dietary habits. However, fetal sex was assessed in a small subgroup (female $n=46$, male $n=37$ ) and female-bearing mothers were over-represented in our cohort, which might limit the representativeness of the results. The cohort included fewer obese than overweight women, which may have affected the results, especially if the associations with BMI are not linear over the whole BMI range. We also lack information on maternal ethnicity, hence, the study needs replication in defined ethnic groups.

\section{Materials and Methods}

\subsection{Study Design and Participants}

This was a secondary, prospective, cross-sectional study conducted in a non-academic setting between May 2017 and August 2018. The study was approved by the ethical committee of the Medical University of Graz (no. 29-095 ex 16/17, 23rd December 2016 and 31-094 ex 18/19, 1 March 2019). All participants provided written informed consent and all methods were performed in accordance with the relevant guidelines and regulations. The study included 123 pregnant women recruited during counseling for voluntary pregnancy termination (gestational age $4^{+0}-11^{+6}$ weeks). Gestational age was defined as days post last menstrual period (LMP) and corroborated by ultrasound measurement of crown-rump length. Inclusion criteria were maternal age $\geq 18$ years, gestational age $<12$ weeks post LMP, and singleton pregnancy. Exclusion criteria were smoking, objectively assessed by serum cotinine measurements, and known co-morbidities, e.g., pre-existing diabetes mellitus, hypertension, auto-immune disease. Cohort characteristics are shown in Table 2.

\subsection{Blood Collection and Storage}

Venous blood $(8 \mathrm{~mL})$ was collected after overnight fasting. The serum fraction was separated by centrifugation $\left(2000 \times \mathrm{g}\right.$ at $4{ }^{\circ} \mathrm{C}$ for $\left.10 \mathrm{~min}\right)$ and immediately stored at $-80^{\circ} \mathrm{C}$ until further use, as previously described [19].

\subsection{Maternal Metabolic Parameters}

Smoking status was assessed by quantification of serum cotinine levels with a competitive immunoassay (Abnova, Taipei, Taiwan Cat\# KA0930) using a cut-off of $\leq 0.03 \mathrm{nmol} / \mathrm{L}$ cotinine for non-smokers [36]. Analytical sensitivity of the assay was $2.5 \mathrm{nmol} / \mathrm{L}$, crossreactivities: nicotine $<1 \%$, nicotinamide $<1 \%$, nicotinic acid $<1 \%$.

Maternal BMI was calculated as weight in kilogram divided by the square of height in meters $\left(\mathrm{kg} / \mathrm{m}^{2}\right)$, both measured at the time of blood collection, and used as an indicator of maternal overweight and obesity. Serum leptin $(\mathrm{ng} / \mathrm{mL})$ was measured by a sandwich immunoassay (DRG, Marburg, Germany, Cat\# EIA2395) and used as a proxy for maternal fat mass. Intra-assay and inter-assay CVs were $6.2 \%$ and $6.6 \%$, respectively. Analytical sensitivity was $0.7 \mathrm{ng} / \mathrm{mL}$ and recovery was $93.5 \%$ with no cross-reactivity with human insulin, proinsulin, C-peptide, glucagon, or IGF-I. 
Table 2. Characteristics of study participants $(\mathrm{N}=123)$.

\begin{tabular}{|c|c|c|c|}
\hline & n $(\%)$ & Mean \pm SD & Median (IQR) \\
\hline Age (years) & 122 & $31.4( \pm 7.2)$ & \\
\hline Gestational age (days) & 123 & $51.0( \pm 15.4)$ & \\
\hline 4-6 weeks & $58(47.0 \%)$ & & $35.0(35.0-42.0)$ \\
\hline 7-9 weeks & $48(39.0 \%)$ & & $56.0(51.0-61.0)$ \\
\hline 10-12 weeks & $17(13.8 \%)$ & & $81.0(78.0-82.0)$ \\
\hline $\operatorname{BMI}\left(\mathrm{kg} / \mathrm{m}^{2}\right)$ & 123 & & $22.6(20.6-25.7)$ \\
\hline Under-/normal-weight $\left(<25 \mathrm{~kg} / \mathrm{m}^{2}\right)$ & $85(69.2 \%)$ & & $21.1(19.8-22.8)$ \\
\hline Overweight $\left(25.0-29.9 \mathrm{~kg} / \mathrm{m}^{2}\right)$ & $30(24.4 \%)$ & & $26.9(25.9-27.4)$ \\
\hline Obese $\left(\geq 30.0 \mathrm{~kg} / \mathrm{m}^{2}\right)$ & $8(6.5 \%)$ & & $32.6(31.9-39.5)$ \\
\hline \multicolumn{4}{|c|}{ Metabolic parameters } \\
\hline Leptin (ng/mL) & 123 & & $11.8(7.1-17.4)$ \\
\hline 1st tertile $(<8.5)$ & 41 & & $5.4(3.5-7.1)$ \\
\hline 2nd tertile (8.5-15.3) & 41 & & $12.0(10.2-13.9)$ \\
\hline 3rd tertile $(\geq 15.3)$ & 41 & & $19.6(17.4-28.6)$ \\
\hline Glucose (mmol/L) & 118 & $4.76( \pm 0.85)$ & \\
\hline 1st tertile $(<4.28)$ & 39 & & $4.01(3.65-4.14)$ \\
\hline 2nd tertile (4.28-4.97) & 40 & & $4.65(4.49-4.82)$ \\
\hline 3rd tertile $(\geq 4.97)$ & 39 & & $5.52(5.16-5.98)$ \\
\hline C-peptide (pmol/L) & 123 & & $371.0(281.5-484.9)$ \\
\hline 1st tertile $(<315.4)$ & 41 & & $258.3(218.5-281.7)$ \\
\hline 2nd tertile (315.4-437.8) & 41 & & $371.0(346.6-402.8)$ \\
\hline 3rd tertile $(\geq 437.8)$ & 41 & & $537.0(476.4-621.3)$ \\
\hline $\mathrm{IS}_{\mathrm{HOMA}}$ & 118 & & $0.74(0.53-1.00)$ \\
\hline 1st tertile $(\leq 0.59)$ & 40 & & $0.46(0.36-0.53)$ \\
\hline 2nd tertile $(0.58-0.85)$ & 39 & & $0.73(0.68-0.79)$ \\
\hline 3rd tertile $(>0.85)$ & 39 & & $1.13(1.00-1.41)$ \\
\hline \multicolumn{4}{|c|}{ Fatty acids (mg/L) } \\
\hline Total fatty acids & 123 & $2724.2( \pm 415.4)$ & \\
\hline SFA & 123 & $918.9( \pm 148.2)$ & \\
\hline C 14:0 & 123 & & $22.7(17.3-32.8)$ \\
\hline C 16:0 & 123 & & $618.3(539.4-694.0)$ \\
\hline C 18:0 & 123 & $273.6( \pm 45.5)$ & \\
\hline MUFA & 123 & $610.5( \pm 132.8)$ & \\
\hline C $16: 1$ & 123 & & $54.8(39.7-67.8)$ \\
\hline C $18: 1(n-9)$ & 123 & $546.1( \pm 114.2)$ & \\
\hline C 22:1 (n-9) & 123 & $6.5( \pm 2.8)$ & \\
\hline n-3 PUFA & 123 & $158.0( \pm 28.5)$ & \\
\hline C $18: 3(n-3)$ & 123 & & $10.7(8.7-14.8)$ \\
\hline C $20: 3(n-3)$ & 123 & & $4.9(3.6-7.3)$ \\
\hline C 20:5 (n-3) & 123 & $17.2( \pm 7.3)$ & \\
\hline C 22:5 (n-3) & 123 & $26.6( \pm 9.6)$ & \\
\hline C $22: 6(n-3)$ & 123 & $97.5( \pm 24.1)$ & \\
\hline n-6 PUFA & 123 & $1036.9( \pm 161.8)$ & \\
\hline C $18: 2(n-6)$ & 123 & $751.4( \pm 131.9)$ & \\
\hline C $18: 3(n-6)$ & 123 & & $9.7(7.8-12.9)$ \\
\hline C 20:2 (n-6) & 123 & & $6.2(5.0-7.3)$ \\
\hline C $20: 3(n-6)$ & 123 & $45.4( \pm 14.0)$ & \\
\hline C 20:4 (n-6) & 123 & $216.4( \pm 49.7)$ & \\
\hline C 22:4 (n-6) & 123 & $7.4( \pm 2.4)$ & \\
\hline C 22:5 (n-6) & 123 & $5.8( \pm 4.0)$ & \\
\hline
\end{tabular}

Normally distributed variables are presented as the mean \pm SD and those not normally distributed as median (IQR). BMI: Body mass index; gestational age: postmenstrual period; $\mathrm{IS}_{\mathrm{HOMA}}$ : Homeostatic model assessment of insulin sensitivity; SD: standard deviation; IQR: Interquartile range. 
Fasting serum glucose $(\mathrm{mmol} / \mathrm{L})$ was measured using the hexokinase-based test (Glucose HK Gen.3, Roche Diagnostics, Mannheim, Germany) on an automated analyzer (cobas ${ }^{\circledR} 8000$ c701, Roche Diagnostics, Mannheim, Germany).

Fasting serum C-peptide (pmol/L) was measured by a Sandwich Immunoassay (R\&D Systems, Minneapolis, MINN, USA Cat\# DICP00). Intra-assay and inter-assay CVs were $3.1 \%$ and $8.3 \%$, respectively. The analytical sensitivity was $2.88 \mathrm{pmol} / \mathrm{L}$ and recovery was $100.4 \%$. Cross-reactivity of $<0.5 \%$ was observed with recombinant human IGF I, IGF II, insulin, proinsulin, and relaxin.

Fasting serum glucose and fasting C-peptide concentrations were used to calculate the homeostatic model assessment of insulin sensitivity ( IS $_{\mathrm{HOMA}}$ ) [37]:

$$
\text { ISHOMA }=\frac{22.5}{\text { Cpeptide }\left(\frac{p m o l}{l}\right) * \text { glucose }\left(\frac{m g}{d l}\right)}
$$

\subsection{Quantification of Serum Fatty Acids}

Concentrations of serum fatty acids were quantified as previously described [38]. Briefly, serum lipids were extracted in chloroform:methanol (2:1) containing $0.005 \%(w / v)$ BHT and an internal standard of nonadecenoic acid (19:1). The final lipid extracts were evaporated to dryness under vacuum, resuspended in toluene, and subjected to methanolysis for $2.5 \mathrm{~h}$ at $80^{\circ} \mathrm{C}$ in methanol:toluene (4:1) containing acetyl chloride and methylheptadecanoate (C 17:0) as a reference standard. The fatty acid methyl esters were separated and quantified on a Perkin Elmer gas chromatograph (Autosystem; Norwalk, CT, USA), with a flame ionization detector and a $30 \mathrm{~m} \times 0.25 \mathrm{~mm}$ Omegawax capillary column. Nitrogen was used as carrier gas and the fatty acid methyl esters were compared with purified standards (Sigma Chemicals Co., St. Louis, MO, USA). Fatty acid concentrations $(\mathrm{mg} / \mathrm{L})$ were quantified as a function of the corresponding peak areas compared to that of the internal standard.

\subsection{Fetal Sex Determination}

For a subgroup of pregnancies ( $\mathrm{n}=83$ women), placental tissue was available making sex determination possible by following a previously established method [39]. Briefly, placental tissue was homogenized in RLT Plus Buffer (Qiagen, Venlo, The Netherlands) with $1 \% \beta$-Mercaptoethanol ( $v / v$, Merck, Darmstat, Germany) in a tissue lyser (MagNa Lyser, Roche, Basel, Switzerland). RNA was isolated with the AllPrep DNA/RNA/miRNA Universal Kit (Qiagen, Hombrechtikon, Switzerland) according to the manufacturer's instructions. Reverse transcription was performed using the LunaScript ${ }^{\mathrm{TM}} \mathrm{RT}$ SuperMix Kit (New England BioLabs, Frankfurt, Germany). TaqMan Universal PCR Master Mix (Life Technologies, Carlsbad, CA, USA) and the primers DDX3Y (FAM labeled) and XIST (VIC labeled) (Life Technologies, DDX3Y: Hs00965254_gH, XIST: Hs01079824_m1) were used for the RT-qPCR (CFX96 Thermocycler, BioRad Laboratories, Hercules, CA, USA). Cycle threshold $(\mathrm{Ct})$ values were generated by the BioRad CFX Manager 3.1 software and fetal sex was determined based on the $\triangle \mathrm{Ct}$ (XIST Ct-DDX3Y Ct).

\subsection{Exposures and Outcomes}

Primary exposures were maternal obesity (BMI) and fat mass (leptin). Secondary

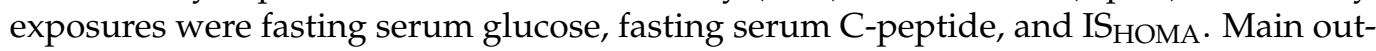
comes were the individual fatty acids, total fatty acids, saturated fatty acids (SFA; myristic acid (C 14:0), palmitic acid (C 16:0), stearic acid (C 18:0)), monounsaturated fatty acids (MUFA; palmitoleic acid (C 16:1), oleic acid (C 18:1), erucic acid (C 22:1)), n-3 polyunsaturated fatty acids ( $n$-3 PUFA; $\alpha$-linolenic acid (C 18:3n-3), eicosatrienoic acid (C 20:3n-3), eicosapentaenoic acid (C 20:5 n-3), docosapentaenoic acid (C 22:5n-3), docosahexaenoic acid (C 22:6n-3)), and $n-6$ polyunsaturated fatty acids (n-6 PUFA; linoleic acid (C 18:2n-6), y-linolenic acid (C 18:3n-6), eicosadienoic acid (C 20:2 $n$-6), dihomo- y-linolenic acid (C 20:3 $n-6)$, arachidonic acid (C 20:4 n-6), adrenic acid (C 22:4 n-6), and osbond acid (C 22:5 n-6)). 
Indices of fatty acid desaturase activity were calculated as product/precursor ratios, i.e., palmitoleic acid (C16:1)/palmitic acid (C16:0) for $\Delta 9$-desaturase, $Y$-linolenic acid (C18:3 n-6)/linoleic acid (C18:2 n-6) for $\Delta 6$-desaturase, arachidonic acid (C20:4)/dihomo$\mathrm{y}$-linolenic acid (C20:3) for $\Delta 5$-desaturase, and arachidonic acid (C20:4 n6)/linoleic acid $(18: 2 n-6)$ for the sum of elongase, $\Delta 5$ - and $\Delta 6$-desaturases activity [40-42].

\subsection{Statistical Analyses}

Normal distribution of variables was assessed visually with histograms and Q-Q plots and by comparison of mean and median values. Skewed data were $\ln$-transformed prior to analysis. Normally distributed variables are presented as the mean \pm SD and non-normally distributed variables as median and IQR.

Associations between metabolic parameters (BMI, leptin, glucose, C-peptide, and $\left.\mathrm{IS}_{\mathrm{HOMA}}\right)$ and maternal serum fatty acids were explored using multivariate linear regression analysis. In the first step, the exposures were analyzed in a continuous and categorical model to test the assumption of linearity. In subsequent analyses, exposures were categorized, when the associations between exposures and outcomes were not linear (assessed by comparison of $\beta$ estimates between dummy variables). Cut-off values of the categories were based on accepted criteria (under-/normal-weight: BMI $<24.9 \mathrm{~kg} / \mathrm{m}^{2}$, overweight: BMI $25-29.9 \mathrm{~kg} / \mathrm{m}^{2}$, obese: BMI $\geq 30 \mathrm{~kg} / \mathrm{m}^{2}$ ) [43], or on tertiles, when there were no established cut-off points (leptin: leptin $<8.5 \mathrm{ng} / \mathrm{mL}$, leptin $8.5-15.3 \mathrm{ng} / \mathrm{mL}$, leptin $\geq 15.3 \mathrm{ng} / \mathrm{mL}$; glucose: glucose $<4.28 \mathrm{mmol} / \mathrm{L}$, glucose $4.28-4.97 \mathrm{mmol} / \mathrm{L}$, glucose $\geq 4.97 \mathrm{mmol} / \mathrm{L} ; \mathrm{C}$-peptide: C-peptide < $315.4 \mathrm{pmol} / \mathrm{L}$, C-peptide $315.4-437.8 \mathrm{pmol} / \mathrm{L}$, C-peptide $\geq 437.8 \mathrm{pmol} / \mathrm{L}$; IS $_{\text {HOMA }}:$ IS $_{\text {HOMA }} \leq 0.59$, IS $_{\text {HOMA }} 0.58-0.85$, IS $\left._{\text {HOMA }}>0.85\right)$ [19]. The most favorable category (1st tertile of leptin, glucose, and C-peptide 3rd tertile for IS $_{\mathrm{HOMA}}$ ) was used as reference.

To test for potential influences of gestational age on total fatty acids, SFA, MUFA, $n-3$, and $n-6$ PUFA concentrations, gestational age was added as a continuous and categorical variable to the models (gestational age: weeks 4-6, weeks 7-9, weeks 10-12). Based on $\beta$-estimates, the associations with gestational age were linear and, therefore, gestational age was further used as a continuous covariate. Statistical interactions between gestational age and BMI, leptin, glucose, $\mathrm{C}$-peptide, and $\mathrm{IS}_{\mathrm{HOMA}}$, respectively, were not significant (for all: $p>0.1$ ).

In a first model, the a priori defined covariates gestational age (days), maternal age (years), and processing time (minutes) were included. In a second model, BMI was added as a covariate to examine a potential confounding effect in the associations between fatty acids and glucose, $\mathrm{C}$-peptide, and $\mathrm{IS}_{\mathrm{HOMA}}$. Leptin replaced BMI in a third model.

The Mann-Whitney $U$ test was used to assess the representativeness of the sub-group $(n=83)$ for which fetal sex data was available with respect to the total cohort $(n=123)$. The Mann-Whitney U test was also used to compare maternal metabolic parameters between mothers bearing a female or a male fetus. Interactions between fetal sex and BMI, leptin, glucose, C-peptide, and IS $\mathrm{H}_{\mathrm{HOMA}}$, respectively, were tested by including both variables and all covariates in the regression model and an interaction term. If the interaction term was significant $(p<0.1)$, associations between exposures (BMI, leptin, glucose, C-peptide, and $\mathrm{IS}_{\mathrm{HOMA}}$ ) and outcomes (fatty acids) were examined in the female-bearing or male-bearing subgroups separately, using the above-described linear regression models.

A $p$-value $<0.05$ was considered statistically significant, except for interaction terms, where a $p$-value $p<0.1$ was considered significant. Furthermore, for the associations with fatty acids, the Benjamini-Hochberg procedure was applied to correct for multiple testing $(\mathrm{FDR}=0.2)$, and in the results, it is always indicated whether a $p$-value was below the critical value for statistical significance.

Data analyses were conducted in IBM SPSS statistics (version 25, IBM Corp, Armonk, NY, USA) and graphs were produced using GraphPad Prism (version 8.4.2, GraphPad Software, San Diego, CA, USA). 


\section{Conclusions}

In conclusion, maternal C-peptide and insulin sensitivity (IS HOMA $_{\text {), but not proxies }}$ of obesity such as BMI or leptin, associate with serum n-3 PUFA. Pregnant women (week $4^{+0}-11^{+6}$ ) with a high C-peptide concentration and low insulin sensitivity (IS HOMA $_{\text {) }}$ ) had decreased serum concentration of total $n-3$ PUFA and docosahexaenoic acid (DHA, C 22:6n-3). Furthermore, we found an association between C-peptide and docosahexaenoic (DHA, C 22:6n-3) acid in female-bearing mothers, but not in male-bearing mothers. If confirmed in a larger cohort, these results add to the growing evidence that fetal sex influences metabolism in pregnant women.

Supplementary Materials: The following are available online at https:/ /www.mdpi.com/article/ $10.3390 /$ ijms221910422/s1.

Author Contributions: Conceptualization, J.B.-M., G.D. and E.H.; methodology, J.B.-M. and M.M.; formal analysis, J.B.-M. and M.N.M.v.P.; resources, A.G.; writing — original draft preparation, J.B.-M. and G.D.; writing-review and editing, J.B.-M., A.M.-M., D.H., M.M., A.G., M.N.M.v.P.; G.D. and E.H.; visualization, J.B.-M.; supervision, G.D.; funding acquisition, G.D. and E.H. All authors have read and agreed to the published version of the manuscript.

Funding: J.B.M. received funding from the Austrian Science Fund 339 FWF (DOC 31-B26) and the Medical University Graz through the PhD Program Inflammatory Disorders in Pregnancy (DPiDP). D.H. received funding from the Austrian Science Fund 341 FWF (W1241) and the Medical University Graz through the PhD Program Molecular Inflammation 342 (MOLIN). A.M.M and G.D. are supported by a fund of the Österreichische Nationalbank, Vienna (Anniversary Fund, project number: 17950). M.M. and E.H. received funding from University San Pablo CEU.

Institutional Review Board Statement: The study was conducted according to the guidelines of the Declaration of Helsinki, and approved by the Institutional Review Board and the Ethical Committee of the Medical University of Graz (29-095 ex 16/17, 23 December 2016 and 31-094 ex 19/19, 1 March 2019).

Informed Consent Statement: Informed consent was obtained from all subjects involved in the study.

Data Availability Statement: The data presented in this study are available on request from the corresponding author. The data are not publicly available due to privacy/ethical restrictions.

Acknowledgments: The authors would like to thank Renate Michlmaier for her support and technical expertise and Monika Stubitsch for her administrative assistance. Open Access Funding by the Austrian Science Fund (FWF).

Conflicts of Interest: The authors declare no conflict of interest. The funders had no role in the design of the study; in the collection, analyses, or interpretation of data; in the writing of the manuscript, or in the decision to publish the results.

\section{References}

1. Edlow, A.G. Maternal Obesity and Neurodevelopmental and Psychiatric Disorders in Offspring. Prenat. Diagn. 2017, 37, 95-110. [CrossRef]

2. Catalano, P.M.; Presley, L.; Minium, J.; Hauguel-de Mouzon, S. Fetuses of Obese Mothers Develop Insulin Resistance in Utero. Diabetes Care 2009, 32, 1076-1080. [CrossRef]

3. Hu, Z.; Tylavsky, F.A.; Han, J.C.; Kocak, M.; Fowke, J.H.; Davis, R.L.; Lewinn, K.; Bush, N.R.; Zhao, Q. Maternal Metabolic Factors during Pregnancy Predict Early Childhood Growth Trajectories and Obesity Risk: The CANDLE Study. Int. J. Obes. 2019, 43, 1914-1922. [CrossRef] [PubMed]

4. Desoye, G.; Herrera, E. Adipose Tissue Development and Lipid Metabolism in the Human Fetus: The 2020 Perspective Focusing on Maternal Diabetes and Obesity. Prog. Lipid Res. 2021, 81, 101082. [CrossRef] [PubMed]

5. Chu, S.Y.; Callaghan, W.M.; Kim, S.Y.; Schmid, C.H.; Lau, J.; England, L.J.; Dietz, P.M. Maternal Obesity and Risk of Gestational Diabetes Mellitus. Diabetes Care 2007, 30, 2070-2076. [CrossRef] [PubMed]

6. Hotamisligil, G.S. Inflammation and Metabolic Disorders. Nature 2006, 444, 860-867. [CrossRef]

7. Metzger, B.E.; Contreras, M.; Sacks, D.A.; Watson, W.; Dooley, S.L.; Foderaro, M.; Niznik, C.; Bjaloncik, J.; Catalano, P.M.; Dierker, L.; et al. Hyperglycemia and Adverse Pregnancy Outcomes. N. Engl. J. Med. 2015, 358, 1991-2002. [CrossRef] 
8. Andrews, C.; Monthé-Drèze, C.; Sacks, D.A.; Ma, R.C.W.; Tam, W.H.; McIntyre, H.D.; Lowe, J.; Catalano, P.; Sen, S. Role of Maternal Glucose Metabolism in the Association between Maternal BMI and Neonatal Size and Adiposity. Int. J. Obes. 2020, 45, 515-524. [CrossRef]

9. Barbour, L.A. Maternal Lipids and Fetal Overgrowth: Making Fat from Fat. Clin. Ther. 2018, 40, 1638-1647. [CrossRef]

10. Barbour, L.A. Metabolic Culprits in Obese Pregnancies and Gestational Diabetes Mellitus: Big Babies, Big Twists, Big Picture. Diabetes Care 2019, 42, 718-726. [CrossRef]

11. Herrera, E.; Ortega-Senovilla, H. Implications of Lipids in Neonatal Body Weight and Fat Mass in Gestational Diabetic Mothers and Non-Diabetic Controls. Curr. Diabetes Rep. 2018, 18, 7. [CrossRef] [PubMed]

12. Steenweg-De Graaff, J.C.J.; Tiemeier, H.; Basten, M.G.J.; Rijlaarsdam, J.; Demmelmair, H.; Koletzko, B.; Hofman, A.; Jaddoe, V.W.V.; Verhulst, F.C.; Roza, S.J. Maternal LC-PUFA Status during Pregnancy and Child Problem Behavior: The Generation R Study. Pediatric Res. 2015, 77, 489-497. [CrossRef] [PubMed]

13. Zou, R.; el Marroun, H.; Voortman, T.; Hillegers, M.; White, T.; Tiemeier, H. Maternal Polyunsaturated Fatty Acids during Pregnancy and Offspring Brain Development in Childhood. Am. J. Clin. Nutr. 2021, 114, 124-133. [CrossRef]

14. Desoye, G.; Schweditsch, M.O.; Pfeiffer, K.P.; Zechner, R.; Kostner, G.M. Correlation of Hormones with Lipid and Lipoprotein Levels During Normal Pregnancy and Postpartum. Clin. Endocrinol. Metab. 1987, 64, 704-712. [CrossRef]

15. Lain, K.Y.; Catalano, P.M. Metabolic Changes in Pregnancy. Clin. Obstet. Gynecol. 2007, 50, 938-948. [CrossRef]

16. Herrera, E.; Amusquivar, E.; López-Soldado, I.; Ortega, H. Maternal Lipid Metabolism and Placental Lipid Transfer. Horm. Res. 2006, 65, 59-64. [CrossRef]

17. Scifres, C.M.; Catov, J.M.; Simhan, H.N. The Impact of Maternal Obesity and Gestational Weight Gain on Early and Mid-Pregnancy Lipid Profiles. Obesity 2014, 22, 932-938. [CrossRef]

18. Penfield-Cyr, A.; Monthe-Dreze, C.; Smid, M.C.; Sen, S. Maternal BMI, Mid-Pregnancy Fatty Acid Concentrations, and Perinatal Outcomes. Clin. Ther. 2018, 40, 1659-1667. [CrossRef]

19. Bandres-Meriz, J.; Dieberger, A.M.; Hoch, D.; Pöchlauer, C.; Bachbauer, M.; Glasner, A.; Niedrist, T.; vann Poppel, M.N.; Desoye, G. Maternal Obesity Affects the Glucose-Insulin Axis during the First Trimester of Human Pregnancy. Front. Endocrinol. 2020, 11, 566673. [CrossRef] [PubMed]

20. Blüher, M. Metabolically Healthy Obesity. Endocr. Rev. 2020, 41, 405-420. [CrossRef] [PubMed]

21. Al-Qaraghouli, M.; Fang, Y.M.V. Effect of Fetal Sex on Maternal and Obstetric Outcomes. Front. Pediatrics 2017, 5, 144. [CrossRef]

22. Lima, R.A.; Desoye, G.; Simmons, D.; Devlieger, R.; Galjaard, S.; Corcoy, R.; Adelantado, J.M.; Dunne, F.; Harreiter, J.; KautzkyWiller, A.; et al. Temporal Relationships between Maternal Metabolic Parameters with Neonatal Adiposity in Women with Obesity Differ by Neonatal Sex: Secondary Analysis of the DALI Study. Pediatric Obes. 2020, 15, e12628. [CrossRef]

23. Retnakaran, R.; Kramer, C.K.; Ye, C.; Kew, S.; Hanley, A.J.; Connelly, P.W.; Sermer, M.; Zinman, B. Fetal Sex and Maternal Risk of Gestational Diabetes Mellitus: The Impact of Having a Boy. Diabetes Care 2015, 38, 844-851. [CrossRef] [PubMed]

24. Metzger, B.E.; Gabbe, S.G.; Persson, B.; Buchanan, T.A.; Catalano, P.A.; Damm, P.; Dyer, A.R.; de Leiva, A.; Hod, M.; Kitzmiler, J.L.; et al. International Association of Diabetes and Pregnancy Study Groups Recommendations on the Diagnosis and Classification of Hyperglycemia in Pregnancy. Diabetes Care 2010, 33, 676-682. [CrossRef] [PubMed]

25. Scaglioni, S.; Verduci, E.; Salvioni, M.; Bruzzese, M.G.; Radaelli, G.; Zetterström, R.; Riva, E.; Agostoni, C. Plasma Long-Chain Fatty Acids and the Degree of Obesity in Italian Children. Acta Paediatr. Int. J. Paediatr. 2006, 95, 964-969. [CrossRef] [PubMed]

26. Micallef, M.; Munro, I.; Phang, M.; Garg, M. Plasma N-3 Polyunsaturated Fatty Acids Are Negatively Associated with Obesity. Br. J. Nutr. 2009, 102, 1370-1374. [CrossRef]

27. Mohammadi, E.; Rafraf, M.; Farzadi, L.; Asghari-Jafarabadi, M.; Sabour, S. Effects of Omega-3 Fatty Acids Supplementation on Serum Adiponectin Levels and Some Metabolic Risk Factors in Women with Polycystic Ovary Syndrome. Asia Pac. J. Clin. Nutr. 2012, 21, 511-518. [CrossRef]

28. Liu, H.Q.; Qiu, Y.; Mu, Y.; Zhang, X.J.; Liu, L.; Hou, X.H.; Zhang, L.; Xu, X.N.; Ji, A.L.; Cao, R.; et al. A High Ratio of Dietary n-3/n-6 Polyunsaturated Fatty Acids Improves Obesity-Linked Inflammation and Insulin Resistance through Suppressing Activation of TLR4 in SD Rats. Nutr. Res. 2013, 33, 849-858. [CrossRef]

29. Alvarado, F.; Tsai, P.; Miinium, J.; Catalano, P.; O’Tierney-Ginn, P. High Maternal DHA Levels in Hawaiian Women Decrease Insulin Resistance. Diabetes 2018, 67, 1404. [CrossRef]

30. Kalupahana, N.S.; Claycombe, K.J.; Moustaid-Moussa, N. (N-3) Fatty Acids Alleviate Adipose Tissue Inflammation and Insulin Resistance: Mechanistic Insights. Adv. Nutr. 2011, 2, 304-316. [CrossRef]

31. Sedlmeier, E.M.; Brunner, S.; Much, D.; Pagel, P.; Ulbrich, S.E.; Meyer, H.H.D.; Amann-Gassner, U.; Hauner, H.; Bader, B.L. Human Placental Transcriptome Shows Sexually Dimorphic Gene Expression and Responsiveness to Maternal Dietary N-3 Long-Chain Polyunsaturated Fatty Acid Intervention during Pregnancy. BMC Genom. 2014, 15, 941. [CrossRef] [PubMed]

32. Simon, J.A.; Fong, J.; Bernert, J.T.; Browner, W.S. Relation of Smoking and Alcohol Consumption to Serum Fatty Acids. Am. J. Epidemiol. 1996, 144, 325-334. [CrossRef]

33. Sowell, K.; Holt, R.; Uriu-Adams, J.; Chambers, C.; Coles, C.; Kable, J.; Yevtushok, L.; Zymak-Zakutnya, N.; Wertelecki, W.; Keen, C. Alcohol Consumption and Smoking During Pregnancy Alters Maternal Plasma Fatty Acid Composition: Association with Fetal Alcohol Spectrum Disorders (P11-028-19). Curr. Dev. Nutr. 2019, 3, 989. [CrossRef]

34. Salahuddin, M.; Pérez, A.; Ranjit, N.; Hoelscher, D.M.; Kelder, S.H. The Effect of Prenatal Maternal Cigarette Smoking on Children's BMI z-Score with SGA as a Mediator. Int. J. Obes. 2018, 42, 1008-1018. [CrossRef] 
35. Albers, L.; Sobotzki, C.; Kuß, O.; Ajslev, T.; Batista, R.F.; Bettiol, H.; Brabin, B.; Buka, S.L.; Cardoso, V.C.; Clifton, V.L.; et al. Maternal Smoking during Pregnancy and Offspring Overweight: Is There a Dose-Response Relationship? An Individual Patient Data Meta-Analysis. Int. J. Obes. 2018, 42, 1249-1264. [CrossRef]

36. Benowitz, N.L.; Bernert, J.T.; Caraballo, R.S.; Holiday, D.B.; Wang, J. Optimal Serum Cotinine Levels for Distinguishing Cigarette Smokers and Nonsmokers within Different Racial/Ethnic Groups in the United States between 1999 and 2004. Am. J. Epidemiol. 2009, 169, 236-248. [CrossRef] [PubMed]

37. Radaelli, T.; Farrell, K.A.; Huston-Presley, L.; Amini, S.B.; Kirwan, J.P.; McIntyre, H.D.; Catalano, P.M. Estimates of Insulin Sensitivity Using Glucose and C-Peptide from the Hyperglycemia and Adverse Pregnancy Outcome Glucose Tolerance Test. Diabetes Care 2010, 33, 490-494. [CrossRef]

38. Amusquivar, E.; Schiffner, S.; Herrera, E. Evaluation of Two Methods for Plasma Fatty Acid Analysis by GC. Eur. J. Lipid Sci. Technol. 2011, 113, 711-716. [CrossRef]

39. Hoch, D.; Novakovic, B.; Tokic, S.; Saffery, R.; Majali-Martinez, A. Sex Matters: XIST and DDX3Y Gene Expression as a Tool to Determine Fetal Sex in Human First Trimester Placenta. Placenta 2020, 97, 68-70. [CrossRef]

40. Beccarelli, L.M.; Scherr, R.E.; Newman, J.W.; Borkowska, A.G.; Gray, I.J.; Linnell, J.D.; Keen, C.L.; Young, H.M. Associations Among Fatty Acids, Desaturase and Elongase, and Insulin Resistance in Children. J. Am. Coll. Nutr. 2018, 37, 44-50. [CrossRef]

41. Warensjö, E.; Rosell, M.; Hellenius, M.L.; Vessby, B.; De Faire, U.; Risérus, U. Associations between Estimated Fatty Acid Desaturase Activities in Serum Lipids and Adipose Tissue in Humans: Links to Obesity and Insulin Resistance. Lipids Health Dis. 2009, 8, 37. [CrossRef]

42. Moon, Y.A.; Ochoa, C.R.; Mitsche, M.A.; Hammer, R.E.; Horton, J.D. Deletion of ELOVL6 Blocks the Synthesis of Oleic Acid but Does Not Prevent the Development of Fatty Liver or Insulin Resistance. J. Lipid Res. 2015, 55, 2597-2605. [CrossRef]

43. World Health Organization. BMI Classification. 2017. Available online: https://www.who.int/news-room/fact-sheets/detail/ obesity-and-overweight (accessed on 27 September 2021). 